\title{
An application of the Multilayer Perceptron: Estimation of Global Solar Radiation and the Establishment of Solar Radiation Maps of Togo
}

\author{
Komi Apélété AMOU*, Tchamye Tcha-Esso BOROZE, Sanoussi OURO-DJOBO, \\ Koffi SAGNA, Yaovi Ouézou AZOUMA, Magolmèèna BANNA, Kossi NAPO \\ Solar Energy Laboratory, Department of Physics, Faculty of Sciences, University of Lomé, Lomé, Togo \\ *Corresponding author: mapkamou@yahoo.fr
}

\begin{abstract}
This paper presents a new neural network approach for the generation of synthetic monthly radiation data for nine localities in Togo. The neural model employed is the well-known Multi-Layer Perceptron (MLP) paradigm, in feedback architecture, using a record of historical values for the supervised network training. The method is based on the MLP ability to extract, from a sufficiently general training set, the existing relationships between variables whose interdependence is unknown a priori. Simulation results are compared to the measured values for the three towns where solar irradiation is measured in Togo. The results show that the generated values are of the real values. The method has been developed using data values from Lomé, Atakpamé and Mango, and is generalized to generate data of any location for the establishment of solar maps. Indeed, the proposed methodology is of general applicability to the estimation of highly complex temporal series.
\end{abstract}

Keywords: estimation, neural model multi, Layer Perceptron (MLP), solar radiation maps

Cite This Article: Komi Apélété AMOU, Tchamye Tcha-Esso BOROZE, Sanoussi OURO-DJOBO, Koffi SAGNA, Yaovi Ouézou AZOUMA, Magolmèèna BANNA, and Kossi NAPO, "An application of the Multilayer Perceptron: Estimation of Global Solar Radiation and the Establishment of Solar Radiation Maps of Togo.” Sustainable Energy, vol. 5, no. 1 (2017): 6-15. doi: 10.12691/rse-5-1-2.

\section{Introduction}

Due to uncertainty of availability of fossil fuels, increasing environmental pollution and general awareness amongst the common people, the green sources of energy are being encouraged. The green sources of energy include solar photovoltaic, solar thermal, wind, biomass, small and big hydro, tidal, wave, ocean, etc. Among these sources of energy, wind, solar and hydro are the common ones in use. Actually, solar photovoltaic cost is competitive compared to wind and other green sources of energy. Solar photovoltaic technology is being used commonly for the generation electricity for both grid connected and standalone power systems. For proper, economical and efficient development and utilization of solar energy, an accurate knowledge of the availability and variability of solar radiation intensity both in time and special domain is very critical. The availability of information about the solar radiation in the zone where a solar system is going to be installed is necessary for the designer of solar systems. This information, in case it exists, can be available, in several ways. The most common is in tabular form with a lot of very useful information, usually large solar radiation sequences, but extremely difficult to handle. Another method can be solar radiation maps of the zone where the installation is going to be made. This method is usually more efficient, easy to handle and preferable by the designers, to be used in a first approach in the solar system design and sizing. Many procedures have been developed to draw solar radiation maps. In most cases, to obtain a solar radiation map it is necessary to know the solar radiation of many points spread wide across the real zone of the map where it is going to be drawn. These solar data can be available in several time scales. Usually there are two time scales in which the data are available: daily and hourly scales. Nevertheless, for most of the locations all over the world the records of solar radiation data are nonexistent. Only very few locations have the privilege of having good meteorological stations where records of solar radiation have being registered. In order to know the behavior of solar radiation at the site of interest, long-term data from a nearby location along with empirical, semiempirical, physical, neural networks, wavelets, fractals, etc. techniques are used. Regression type models were first applied to this problem by Angström [1] based on sunshine duration. This model was developed for other locations by Rietveld [2], Newland [3], Gopinathan [4] and Akinoglu and Ecevit [5]. Furthermore, some regression models incorporating trigonometric functions have been proposed by Dorvlo and Ampratwum [6]. One of the limitations imposed by linear regression models is that they will underperform when used to model nonlinear systems. Radiation data being time dependent have also been modeled using harmonic analysis methods by Philips [7] and Herrero [8]. In recent years, Artificial Neural Network (ANN) methods have been employed for the 
prediction of global solar radiation both in time and special domains. Instead of complex rules and mathematical routines mentioned above, ANN model are able to learn the key information patterns within a multidimensional information domain. Furthermore, the neural approach is particularly suitable to solve the problem of identification in the presence of noisy data (Rumelhart et al. [9]; Hertz et al. [10]. Gardner and Dorling [11] concluded that neural networks generally give better results compared with statistical linear methods, especially where the problem being analysed includes nonlinear behavior. Al-Alawi and Al-Hinai [12] have used ANN model to predict solar radiation in areas not covered by direct measurement instrumentation. The input data to the network are the location, month, mean pressure, mean temperature, mean vapor pressure, mean relative humidity, mean wind speed and mean duration of sunshine. The ANN predicts solar radiation with an accuracy of 93\% and mean absolute percentage error of $7.3 \%$. Togrul and Onat [13] used geographical and meteorological parameters along with the ANN methods for the prediction of GSR for a city in Turkey. Kalogirou et al. [14] used a recurrent neural network method to estimate the maximum solar radiation using measured values of air temperature and relative humidity as input. The authors found that the correlation coefficient varied between $98.6 \%$ and $98.8 \%$. Sözen et al. [15] used meteorological and geographical parameters as input into the neural networks model for the prediction solar potential for Turkey. In another study, Yang and Koike [16] utilized upper air humidity values for the estimation of solar radiation on the surface of the earth through ANN method. Other authors used MLP method as can be seen from these references (Elizondo et al. [17]; Al-Alawi and Al-Hinai [12]; Mohandes et al. [18,19]; Togrul and Onat [13]; Hontoria et al. [20,21]; Tasadduq et al. [22]; Kalogirou et al. [14]; Tymvios et al. [23]). The present paper utilizes the air temperature, relative humidity and the latitude of Lomé, Atakpamé and Mango data as input in neural networks for the prediction of global solar irradiation (GSR) on horizontal surfaces in seven other cities in Togo, and to establish its solar maps.

\section{Apparatus and Data Gathering}

Measuring apparatus was installed on the terrace of solar laboratory of University of Lomé and meteorological station of Lomé (lat. 06²10' North and long. 01¹5’ East ), at Lomé, in the terrasse of meteorological stations of

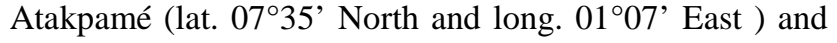
Mango (lat. $10^{\circ} 22^{\prime}$ North and long. 00²8' East). All sensors are installed on the roof-top in a position relatively free from any external obstruction, and readily accessible for inspection and general cleaning. Measurements of global radiation were carried out using good precision pyranometer that respond to radiation within a $2 \pi$ steradian (hemispherical) field of view, which is sensitive in the wavelength range from $0.4 \mu \mathrm{m}$ to $1.1 \mu \mathrm{m}$.

The stations are scheduled to measure the global solar radiation (GSR) from 5:00 a.m. to 8:00 p.m. daily. The GSR is measured every 30 seconds and after one hour, the meter averages and records the hourly values. The air temperature, relative humidity and GSR data respectively are mesured every hour from 2002 to 2009.

Different locations, with different features were taken. In Table 1 these sites, with some of their characteristics are shown. Seven different cities have been chosen. The election of those seven locations was done due to the different position they have. The seven places are cities in Togo with different climates. Also these seven locations have different altitudes upon sea level and their latitudes vary almost 5 , from $6,17^{\circ}$ to $10,88^{\circ}$ North. The hourly air temperature and relative humidity data of these seven locations were recorded by the National Meteorological Institute of Togo.

Table 1. Locations in study

\begin{tabular}{|l|c|c|}
\hline Cities & Longitude( $\left.{ }^{\circ}\right)$ & Latitude( $\left.{ }^{\circ}\right)$ \\
\hline Lomé & 1,25 & 6,17 \\
\hline Tabligbo & 1,50 & 6,58 \\
\hline Kouma-Konda & 0,57 & 6,95 \\
\hline Atakpamé & 1,12 & 7,58 \\
\hline Sokodé & 1,15 & 9,00 \\
\hline Kara & 1,17 & 9,55 \\
\hline Niamtougou & 1,08 & 9,80 \\
\hline Mango & 0,47 & 10,37 \\
\hline Dapaong & 0,25 & 10,88 \\
\hline
\end{tabular}

\section{Methodology}

The interest in ANNs is largely due to their ability to mimic natural intelligence in its learning from experience (Wasserman [24]. They learn from examples by constructing an input-output mapping without explicit derivation of the model equation. ANN have been used in a broad range of applications including: pattern classification (Lippmann [25]; Bishop [26]), function approximation, optimization, prediction and automatic control (Pham and Liu) [27] and many others. Additionally, ANNs have been used extensively for meteorological applications.

The methodology proposed makes use of a neural network system called Multi-Layer Perceptron (MLP) (Haykin [28]; Hornik et al. [29]; Lippmann [25]). This neural network has already been presented in previous works (Hontoria et al. [20,21,30,31]; Zufiria et al. [32]). In those works the capabilities of the MLP to generate synthetic hourly solar radiation series have been demonstrated. Moreover, in comparison with other methods for generating synthetic sequences of solar data, the MLP improves (Hontoria et al.) [20,30] the results obtained by those methods. In this paper, MLP is used for the estimation of GSR based on measured temperature, relative humidity and latitude data.

An ANN consists of many interconnected identical simple processing units called neurons. Each connection to a neuron has an adjustable weight factor associated with it. Every neuron in the network sums its weighted inputs to produce an internal activity level $a_{i}$.

$$
a_{i}=\sum_{j=1}^{n} w_{i j} x_{i j}-w_{i 0}
$$


where $\mathrm{w}_{\mathrm{ij}}$ is the weight of the connection from input $\mathrm{j}$ to neuron $\mathrm{i}, \mathrm{x}_{\mathrm{ij}}$ is input signal number $\mathrm{j}$ to neuron $\mathrm{i}$, and $\mathrm{w}_{\mathrm{i} 0}$ is the threshold associated with unit $i$. The threshold is treated as a normal weight with the input clamped at 1 . The internal activity is passed through a nonlinear function $j$ to produce the output of the neuron yi. Several forms of differentiable activation functions have been used with the most popular being the logistic function of the form:

$$
f(x)=\frac{1}{1+\exp \left(-a_{i}\right)} \text { with } a_{i}>0 .
$$

\subsection{Implementation of the Backpropagation Algorithm}

Step 1: Initialization of connection weights.

These weights are randomly selected.

Step 2: Spread entries: MLP with one hidden layer Propagated from the input layer to the hidden layer:

$$
y_{j}=f\left(\sum_{i=0}^{p} x_{i} v_{i}\right)
$$

Then the hidden layer to the output layer:

$$
Z_{k}=f\left(\sum_{j=1}^{q} y_{j} w_{k j}\right) .
$$

$Z_{k}$ is the output of the network.

The activation function $f$ is the sigmoïd.

Step 3: the error backpropagation

For each example of applied learning based network input, we calculate the error on the output layers.

$$
E_{k}=z_{k}\left(1-z_{k}\right)\left(s_{k}-z_{k}\right)
$$

where $S_{k}$ is the desired output and the actual output is $Z_{k}$.

It propagates this error on the hidden layer. The error of each hidden layer neuron is given by:

$$
F_{j}=y_{j}\left(1-y_{j}\right) \sum_{k=1}^{p} w_{k j} E_{k} .
$$

Step 4: Fixed connection weights

Between the input and the output layer layer:

$$
\Delta w_{k i}=\eta y_{i} E_{k} .
$$

Between the hidden layer and output:

$$
\Delta v_{j i}=\eta x_{i} F_{j}
$$

$\eta$ is a parameter to be determined.

Step 5: Completing step 2 until a stopping criterion to define.

In practice, the search for appropriate weight as possible to approximate the desired results is complex and very long. To do this, neural network simulator is used.

\subsection{Design of a Neural Network}

Neural networks perform nonlinear functions set. Their implementation requires:

- The determination of relevant inputs and outputs, i.e. the quantities that have a significant influence on the phenomenon that one seeks to model.
- The collection of data necessary for learning and evaluating neural network performance.

- Determining the number of hidden neurons necessary to obtain a satisfactory approximation.

- The achievement of learning

- The evaluation of neural network performance at the end of learning.

\subsection{Configuration of Our Neural Network}

Configuration of the neural network. According to our calculations, the annual solar irradiation for a given city depends on such parameters as its latitude, its monthly average relative humidity and average monthly temperature. Thus in the input of the network we have three neurons and one neuron in the output layer. For the hidden layer there is no rule defined for the number of neurons that constitutes it. Simulating the network for different values of the number of neurons in the hidden layer, the optimum results are given for a number of neurons equal to two. Figure 1 shows the configuration of our neural network.

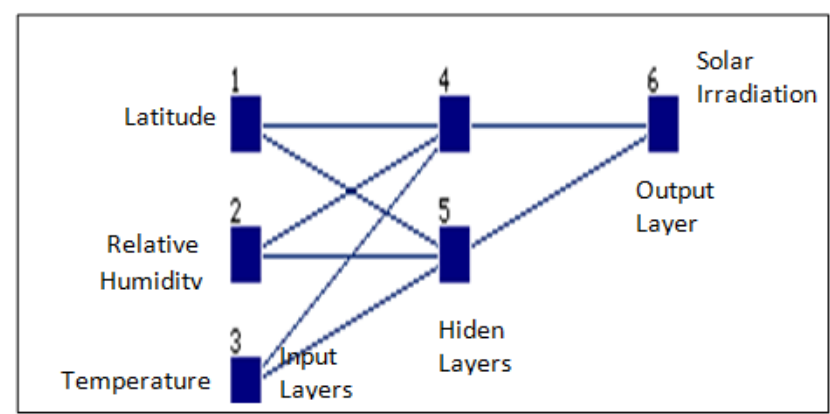

Figure 1. Neural network configuration used

\subsection{Testing and Validation}

While tests involve checking the performance of a sample off neural network and its generalization ability, validation is sometimes used when learning. Once developed neural network, tests are needed to check the forecast quality of the neural model. This last step is designed to estimate the quality of the network obtained by presenting examples that are not part of the training set. A rigorous validation of the developed model results in a significant proportion of correct predictions on all of the validation. If network performance is not satisfactory, it will either alter the architecture of the network or change the learning base.

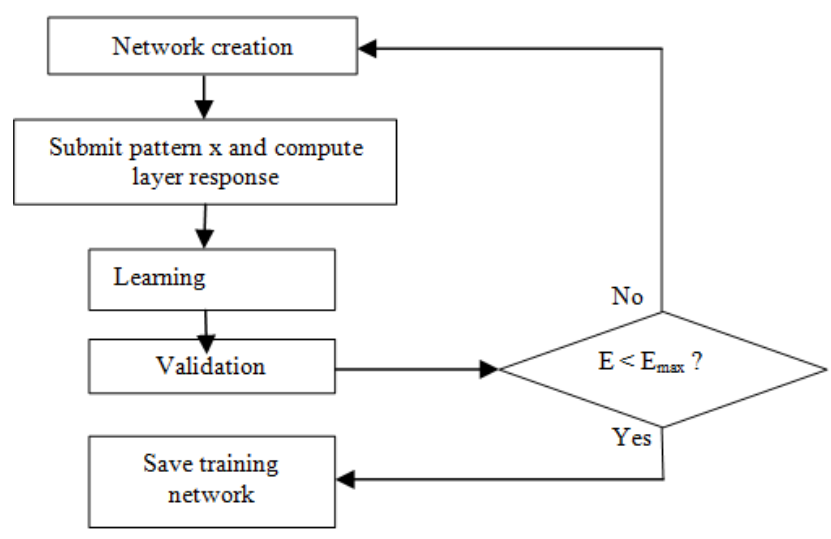

Figure 2. Error back propagation algorithm 


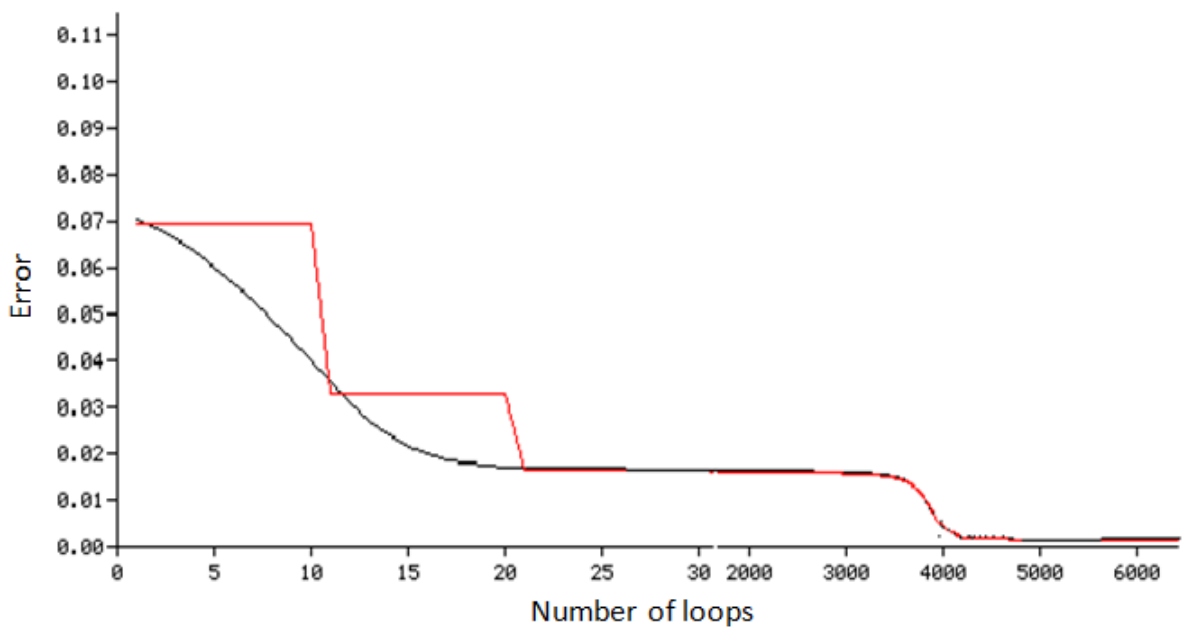

Figure 3. Learning curve and its validation

To ensure the validity of this method, it is essential to monitor the squared error between the desired output and the actual output (Chatelin, C.) [33]. Figure 3 shows the curve obtained for learning data in January. This curve is similar to other curves obtained for different months of the year.

The black curve corresponds to learning and that red is the validation of learning. From 20 periods, both black and red curves are combined. This means that the network has performed learning. But at this stage the square error remains high. Therefore learning was continued and at the end of 6000 loops, the two curves while remaining confused, error became weak. This means that the network is well trained.

\section{Proposed Methodology to Draw Solar Radiation Maps}

The preparation of solar radiation maps requires the previous knowledge of a lot of information, which can be summarised with these steps:
Step 1. Making a grid of the zone that is going to be represented in the map. Each point of the grid corresponds to a certain real site that will have some particular features as its latitude, its longitude and its altitude over sea level, besides the solar radiation data.

Step 2. For each point of that grid knowledge of long sequences of solar radiation is needed.

Step 3. Once the series of solar radiation is available for the entire grid, it is necessary to obtain some particular statistical values to draw the maps. For instance, it is interesting to summarise all that information in 12 maps, one for each month of the year.

\section{Results of the Statistical Evaluation}

The results of learning and simulated values were collected and summarized in the following Table 2. To better compare the measured data and values obtained by the MLP, we calculated the relative error for each month and MPE, MBE and RMSE of the three cities [34,35] (Rude, J., Ammar, M. Y.).

Table 2. Relative error of each month and MPE, MBE and RMSE for each city

\begin{tabular}{|c|c|c|c|c|c|c|c|c|c|}
\hline \multirow[b]{2}{*}{ Months } & \multicolumn{3}{|c|}{ Lomé } & \multicolumn{3}{|c|}{ Atakpamé } & \multicolumn{3}{|c|}{ Mango } \\
\hline & $\begin{array}{l}\text { Mesured } \\
\text { radiation }\end{array}$ & $\begin{array}{c}\text { Simulated } \\
\text { radiation }\end{array}$ & Error \% & $\begin{array}{l}\text { Mesured } \\
\text { radiation }\end{array}$ & $\begin{array}{l}\text { Simulated } \\
\text { radiation }\end{array}$ & $\begin{array}{c}\text { Error } \\
\%\end{array}$ & $\begin{array}{l}\text { Mesured } \\
\text { radiation }\end{array}$ & $\begin{array}{c}\text { Simulated } \\
\text { radiation }\end{array}$ & $\begin{array}{c}\text { Error } \\
\%\end{array}$ \\
\hline January & 3756,9 & 3732,9 & 0,64 & 4377,3 & 4412,9 & 0,81 & 5631,5 & 5608,9 & 0,40 \\
\hline February & 4407,5 & 4409,2 & 0,04 & 4845,2 & 4869,6 & 0,50 & 6041,1 & 6008,5 & 0,54 \\
\hline March & 4782,0 & 4771,9 & 0,21 & 5448,1 & 5483,9 & 0,66 & 6273,1 & 6215,4 & 0,92 \\
\hline April & 4959,7 & 4960,3 & 0,01 & 5370,5 & 5371,8 & 0,02 & 6016,0 & 6008,8 & 0,12 \\
\hline May & 4615,1 & 4694,0 & 1,71 & 5337,0 & 5252,3 & 1,59 & 5641,3 & 5694,2 & 0,94 \\
\hline June & 3788,5 & 3846,7 & 1,54 & 4914,5 & 4776,8 & 2,80 & 5149,2 & 5237,0 & 1,71 \\
\hline July & 3955,1 & 3895,0 & 1,52 & 4003,7 & 4095,7 & 2,30 & 4509,2 & 4488,2 & 0,47 \\
\hline August & 3908,0 & 3846,8 & 1,57 & 3533,5 & 3621,0 & 2,48 & 4363,9 & 4368,6 & 0,11 \\
\hline September & 4498,3 & 4483,3 & 0,33 & 4391,9 & 4427,7 & 0,81 & 4926,0 & 4912,2 & 0,28 \\
\hline October & 4964,5 & 4941,3 & 0,47 & 5140,5 & 5167,1 & 0,52 & 5776,2 & 5745,5 & 0,53 \\
\hline November & 4853,2 & 4904,9 & 1,07 & 5259,1 & 5146,8 & 2,13 & 5396,2 & 5452,0 & 1,03 \\
\hline December & 4193,1 & 4182,9 & 0,24 & 4619,1 & 4655,5 & 0,79 & 5235,0 & 5216,9 & 0,34 \\
\hline MPE & \multicolumn{3}{|c|}{0,78} & \multicolumn{3}{|c|}{1,28} & \multicolumn{3}{|c|}{0,62} \\
\hline MBE & \multicolumn{3}{|c|}{1,05} & \multicolumn{3}{|c|}{$-3,38$} & \multicolumn{3}{|c|}{0,20} \\
\hline RMSE & \multicolumn{3}{|c|}{42,04} & \multicolumn{3}{|c|}{71,49} & \multicolumn{3}{|c|}{41,34} \\
\hline
\end{tabular}


As shown in Table 2 and the Figure 4, Figure 5 and Figure 6 obtained, learning was done in good conditions with acceptable accuracy. From the weight determined after the validation of learning, will be calculated solar radiation data for cities whose monthly temperature data, relative humidity are available in addition to their latitude. After developing new patterns files, data were generated by month. The solar radiation monthly average of localities obtained by neuronal method is reported in the Table 3 .

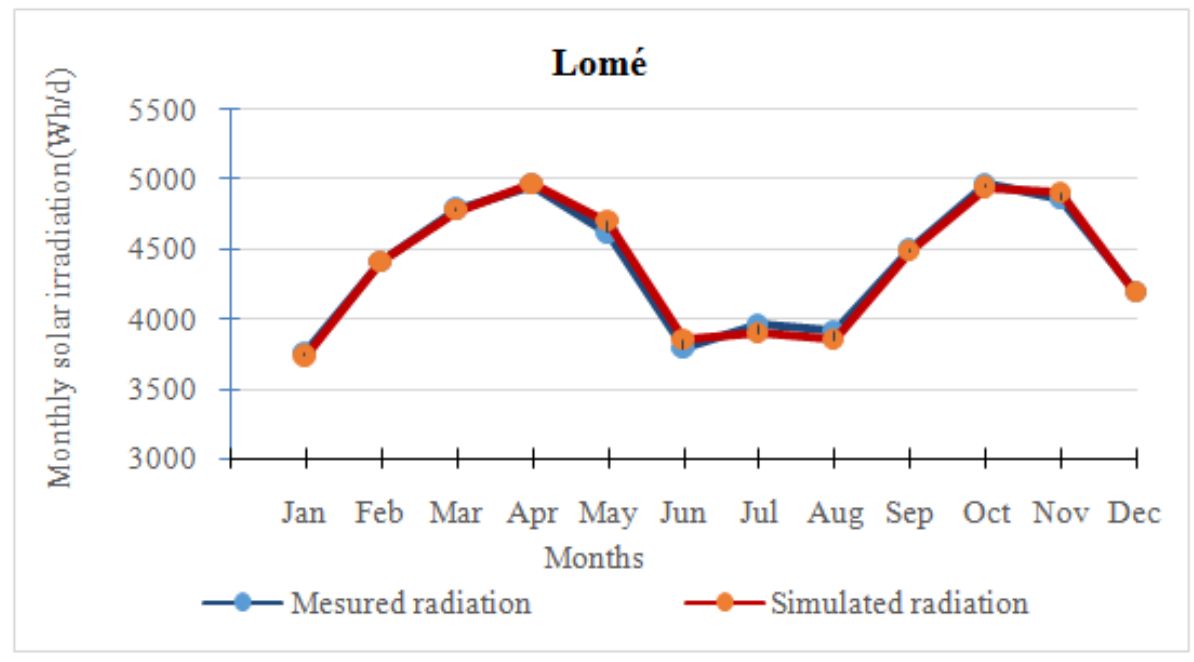

Figure 4. Estimated and simulated data for Lomé

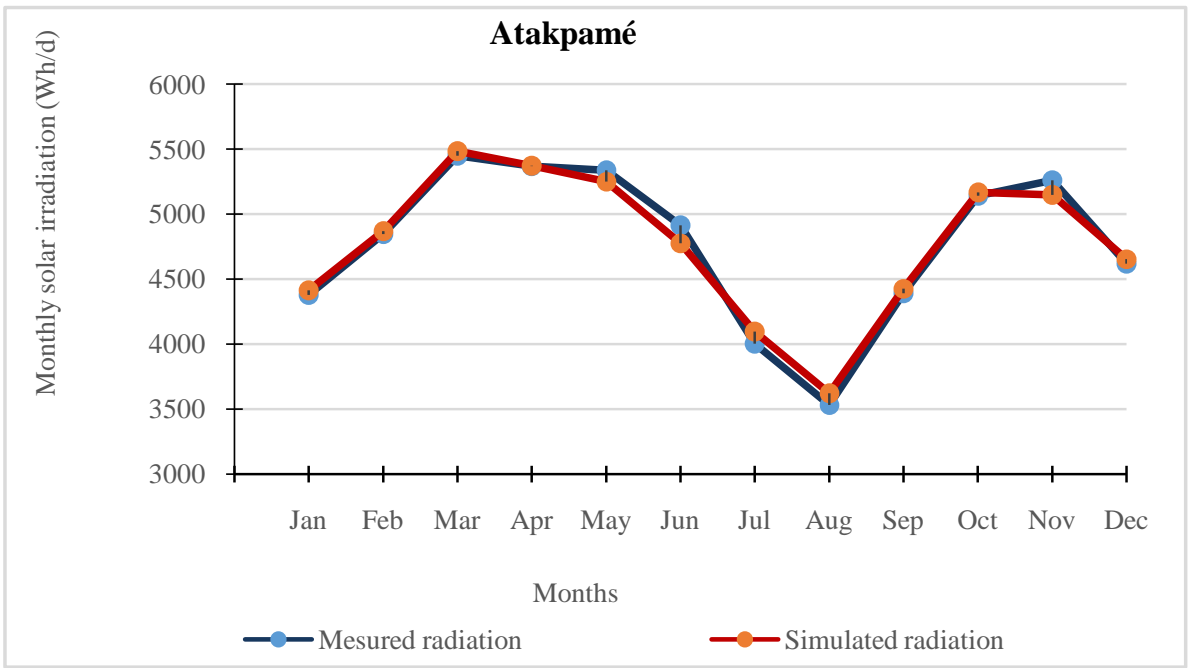

Figure 5. Estimated and simulated data for Atakpamé

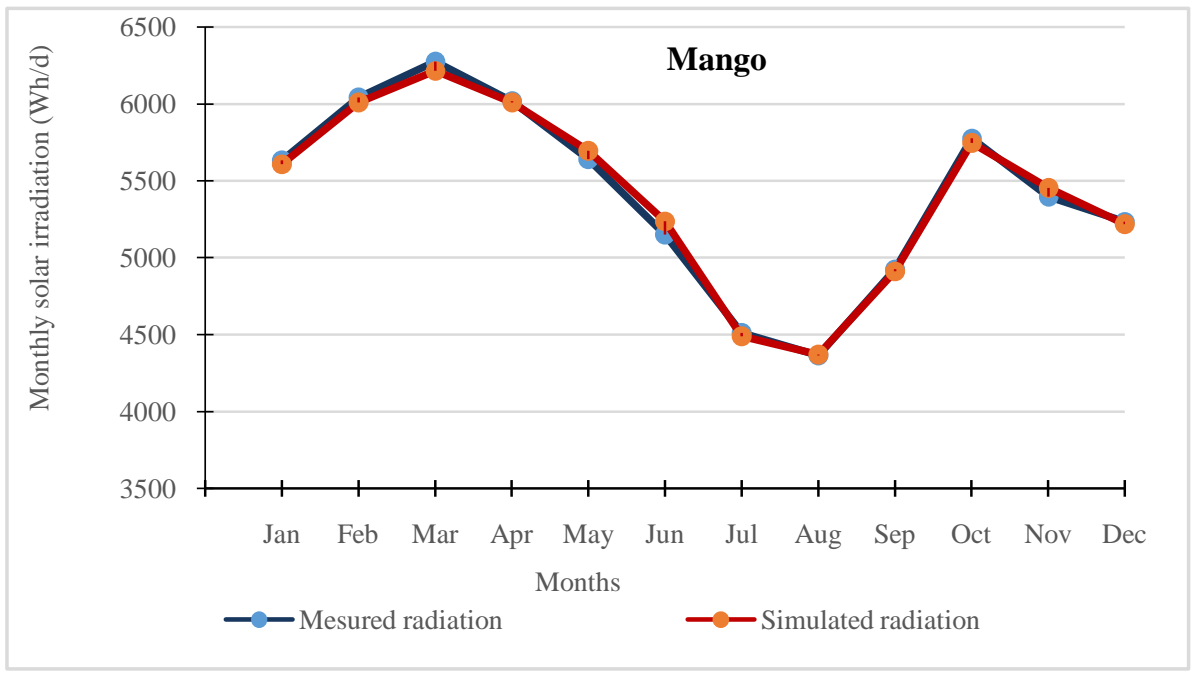

Figure 6. Estimated and simulated data for Mango 
Table 3. The monthly average of solar radiation (Wh $/ \mathrm{m}^{2} /$ day) for different cities in Togo

\begin{tabular}{|l|c|c|c|c|c|c|c|c|c|}
\hline Localities & Lomé & Tabligbo & Kouma-Konda & Atakpamé & Sokodé & Kara & Niamtougou & Mango & Dapaong \\
\hline January & 3747,8 & 3901,7 & 4164,7 & 4349,6 & 4938,2 & 5322,4 & 5420,9 & 5531,5 & 5712,4 \\
\hline February & 4427,4 & 4567,3 & 4698,3 & 4957,8 & 5456,9 & 5838,0 & 5920,8 & 6029,5 & 6136,3 \\
\hline March & 4775,8 & 4986,1 & 5091,3 & 5468,1 & 5844,5 & 6097,3 & 6124,4 & 6211,2 & 6264,5 \\
\hline April & 4967,9 & 5122,3 & 5056,5 & 5379,1 & 5652,1 & 5880,4 & 5815,4 & 5986,6 & 6119,6 \\
\hline May & 4683,5 & 4893,3 & 5036,4 & 5255,8 & 5524,2 & 5639,2 & 5641,6 & 5695,7 & 5744,8 \\
\hline June & 3818,0 & 4150,2 & 4673,5 & 4775,0 & 5114,6 & 5174,0 & 5229,2 & 5237,1 & 5307,8 \\
\hline July & 3895,1 & 3960,4 & 3987,2 & 4098,1 & 4300,7 & 4379,6 & 4405,0 & 4487,5 & 4546,4 \\
\hline August & 3781,5 & 3856,8 & 2918,9 & 3592,1 & 3767,4 & 3991,7 & 3791,0 & 4281,7 & 4059,3 \\
\hline September & 4478,3 & 4435,6 & 4532,9 & 4450,9 & 4743,8 & 4645,3 & 4672,9 & 4905,2 & 4802,7 \\
\hline October & 4941,6 & 5027,5 & 4843,9 & 5166,5 & 5418,2 & 5562,7 & 5560,2 & 5735,2 & 5770,1 \\
\hline November & 4905,3 & 4984,9 & 5041,3 & 5155,7 & 5316,9 & 5397,3 & 5426,4 & 5465,9 & 5527,8 \\
\hline December & 4180,8 & 4324,0 & 4379,4 & 4649,4 & 4910,7 & 5070,8 & 5105,1 & 5212,8 & 5215,1 \\
\hline
\end{tabular}

\section{Solar Radiation Maps}

As the results show, the learning was done in good conditions with an acceptable precision. From the weights determined after the validation of the learning, the solar radiation values will be calculated for the cities whose monthly temperature, relative humidity data are available in addition to their latitude. Thus, the data obtained from meteorology concerns only six other cities covering the Togolese geographical space. Indeed, the National Meteorological Service only has complete data from six

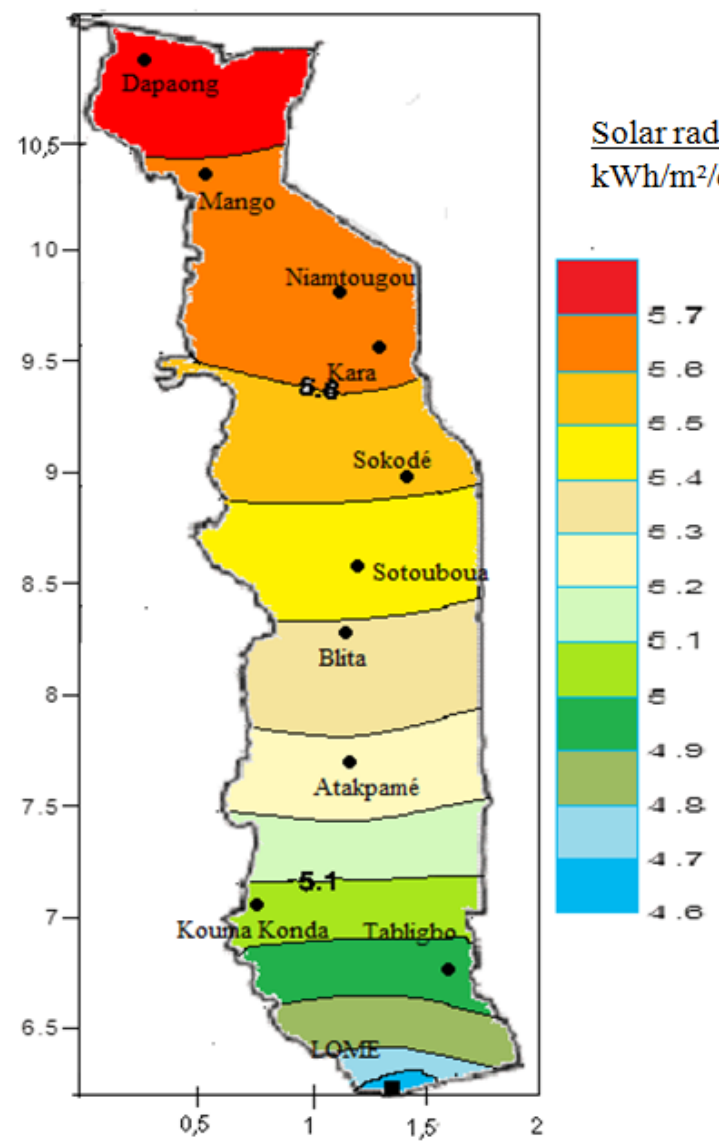

Figure 7. Solar radiation map of Togo in January other cities outside Lomé, Atakpamé and Mango. The geographical coordinates of the cities whose deposit is estimated in Table 1.

A MLP has been trained with hourly solar radiation data of sites in Lomé, Atakpamé and Mango [36] (Hontoria, L.). For those six cities, the National Meteorological Institute provides us 7 years data. As in the previous section the solar global monthly mean values are obtained for each point on the grid, so twelve solar radiation maps (Figure 7 to Figure 18) were drawn (one for each month).

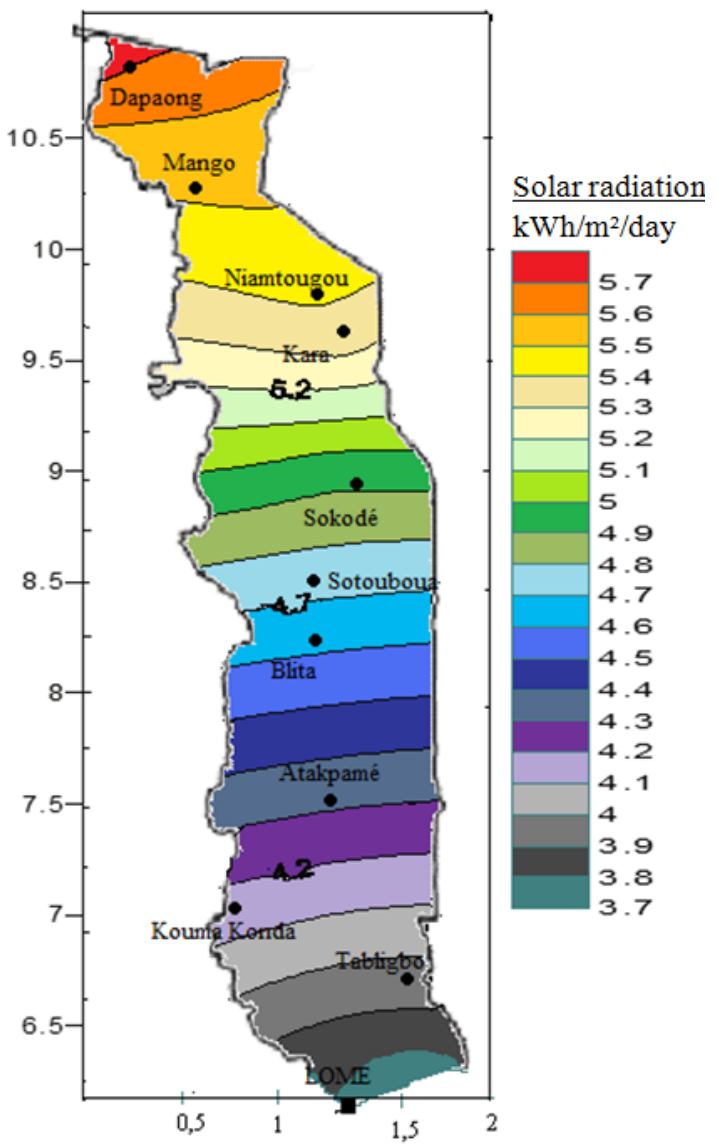

Figure 8. Solar radiation map of Togo in February 

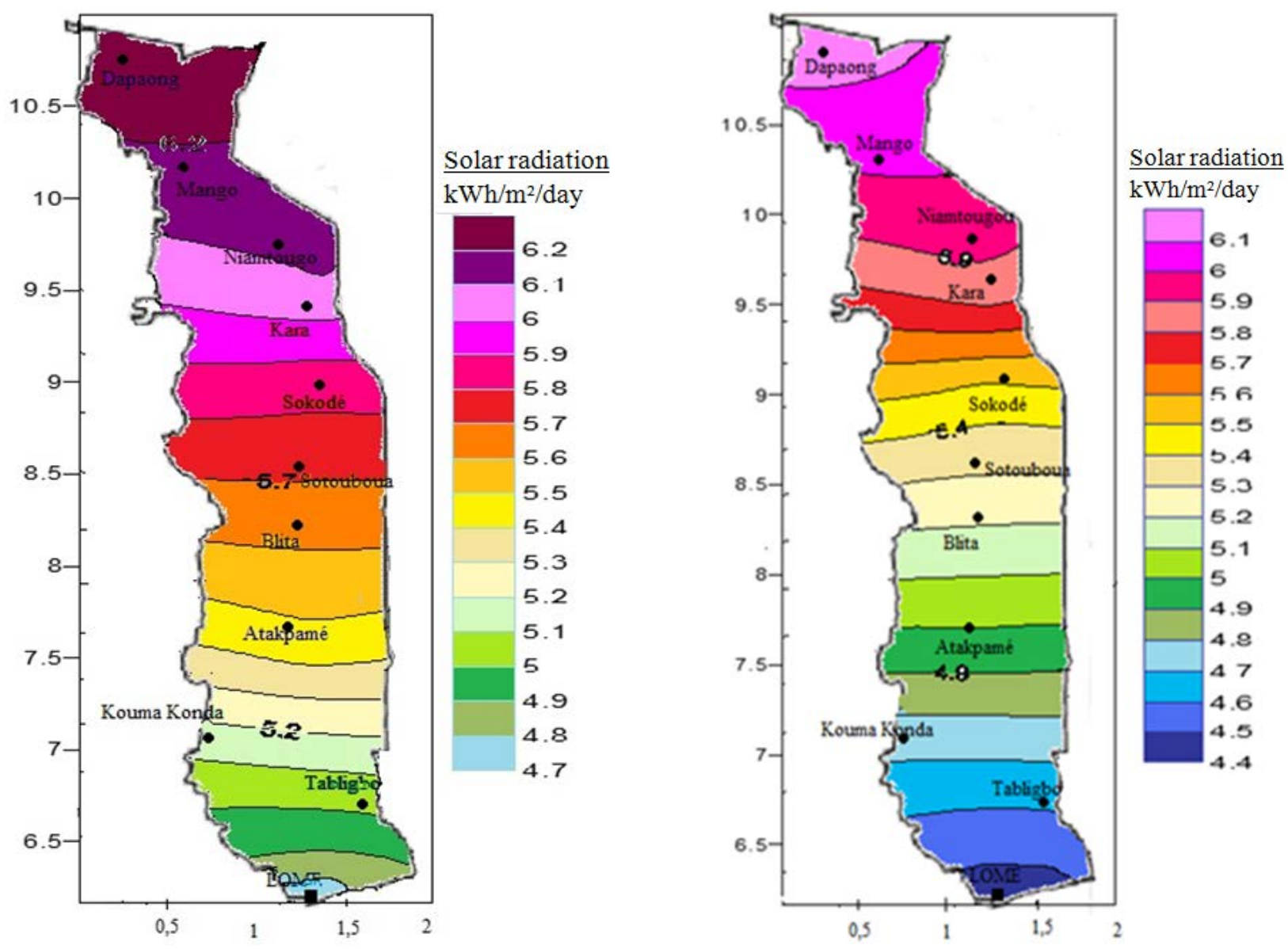

Figure 9. Solar radiation map of Togo in March

Figure 11. Solar radiation map of Togo in May

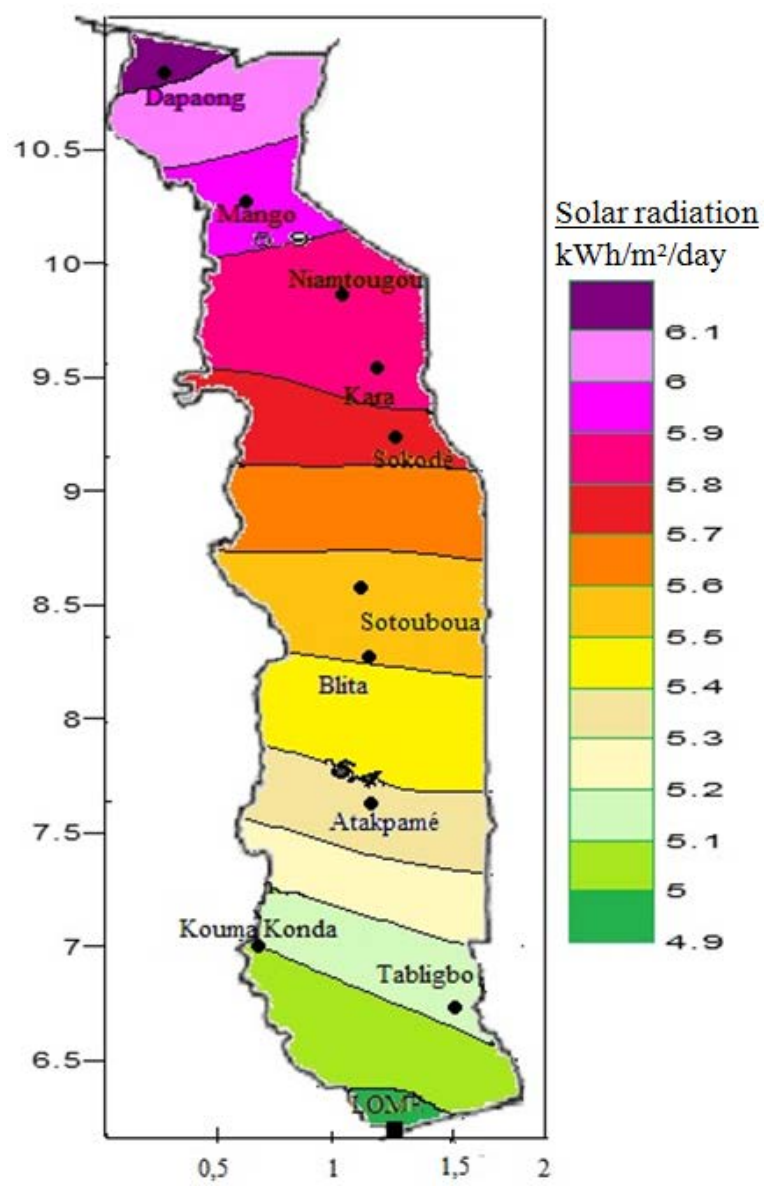

Figure 10. Solar radiation map of Togo in April

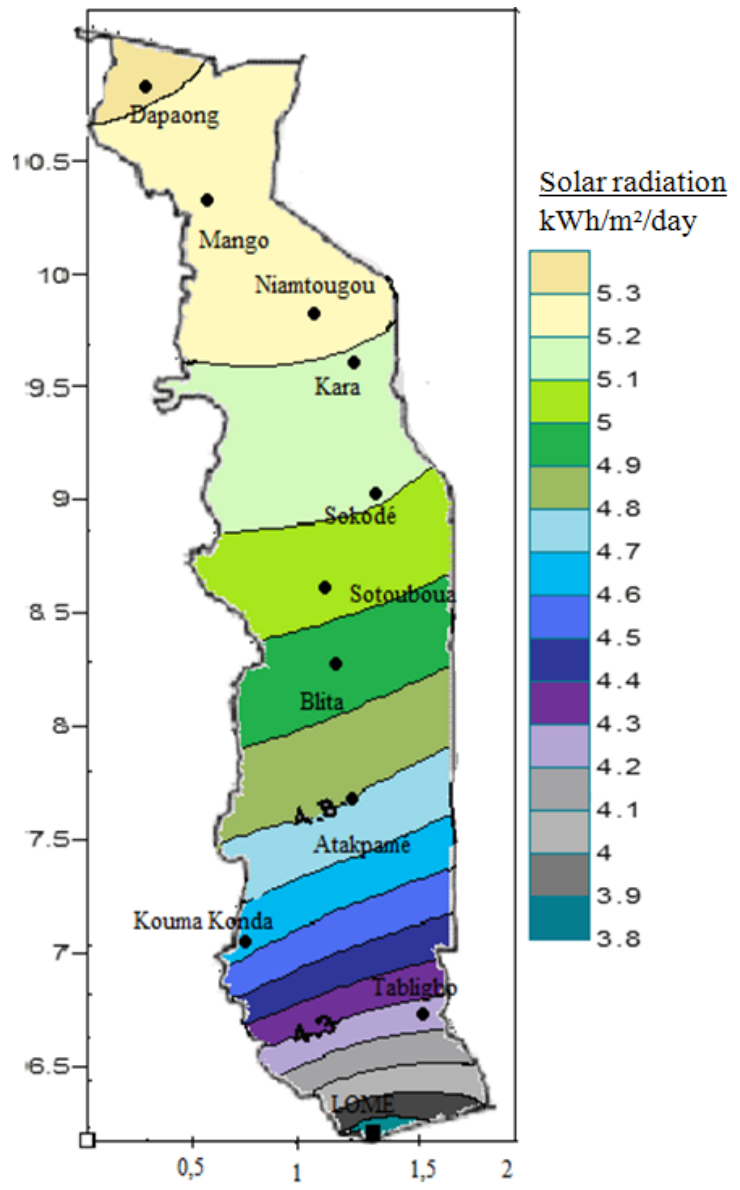

Figure 12. Solar radiation map of Togo in June 


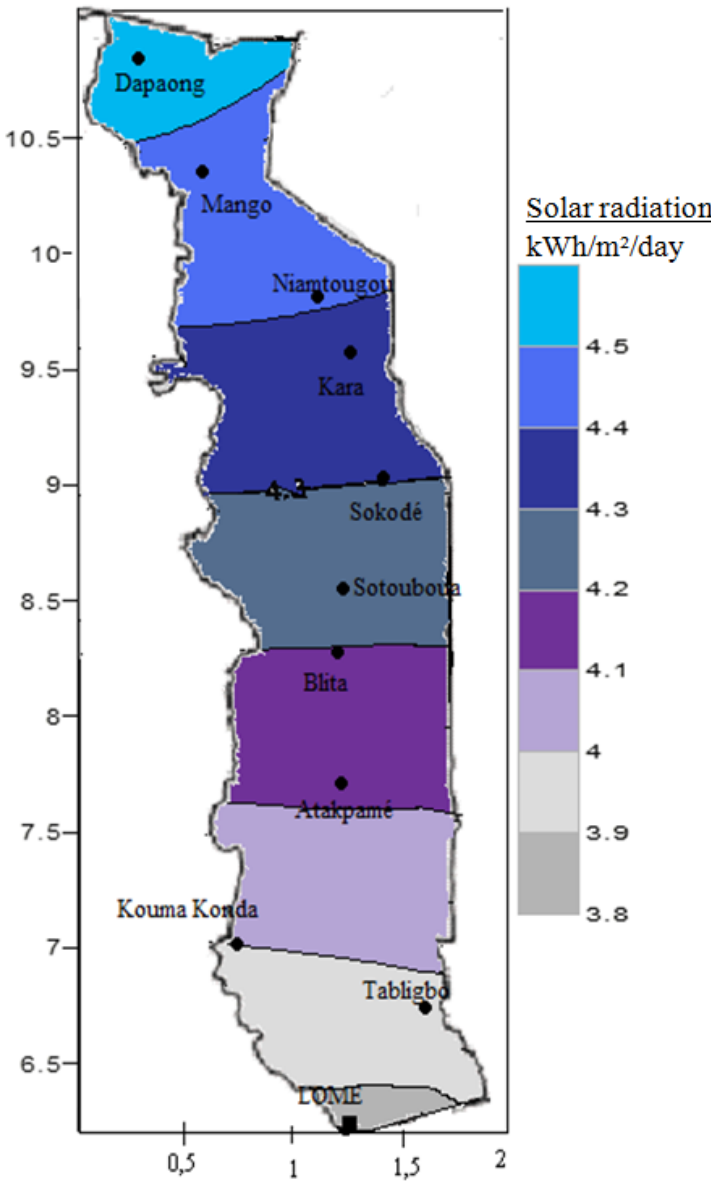

Figure 13. Solar radiation map of Togo in July

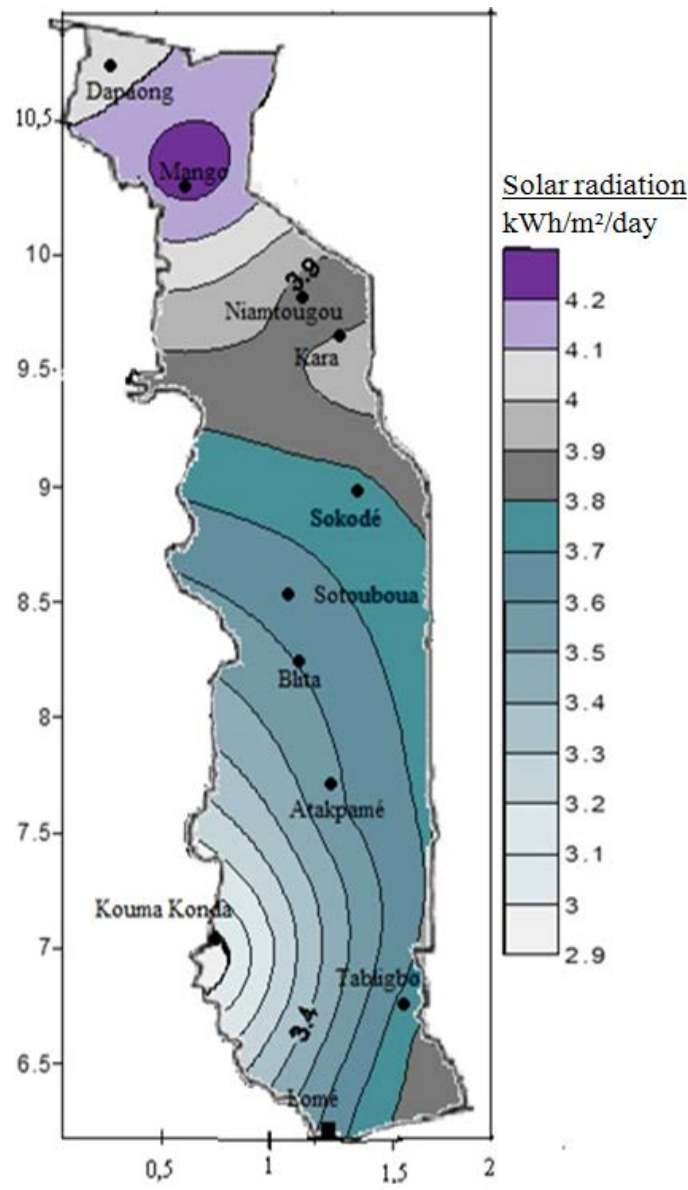

Figure 14. Solar radiation map of Togo in August

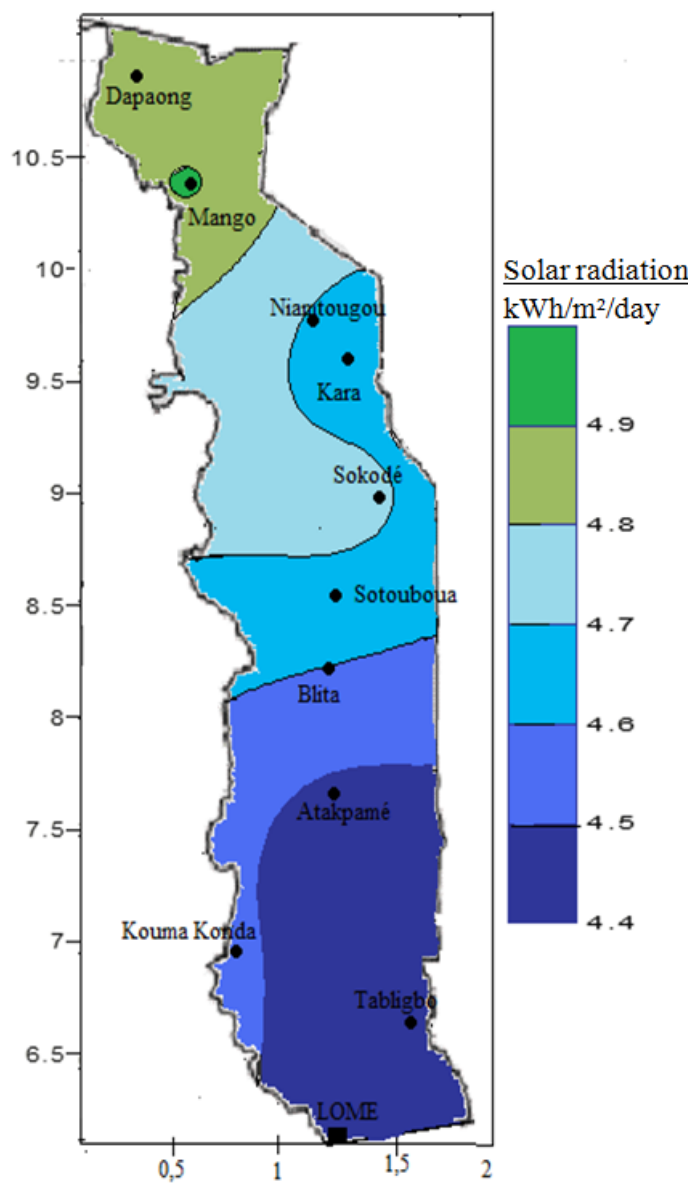

Figure 15. Solar radiation map of Togo in September

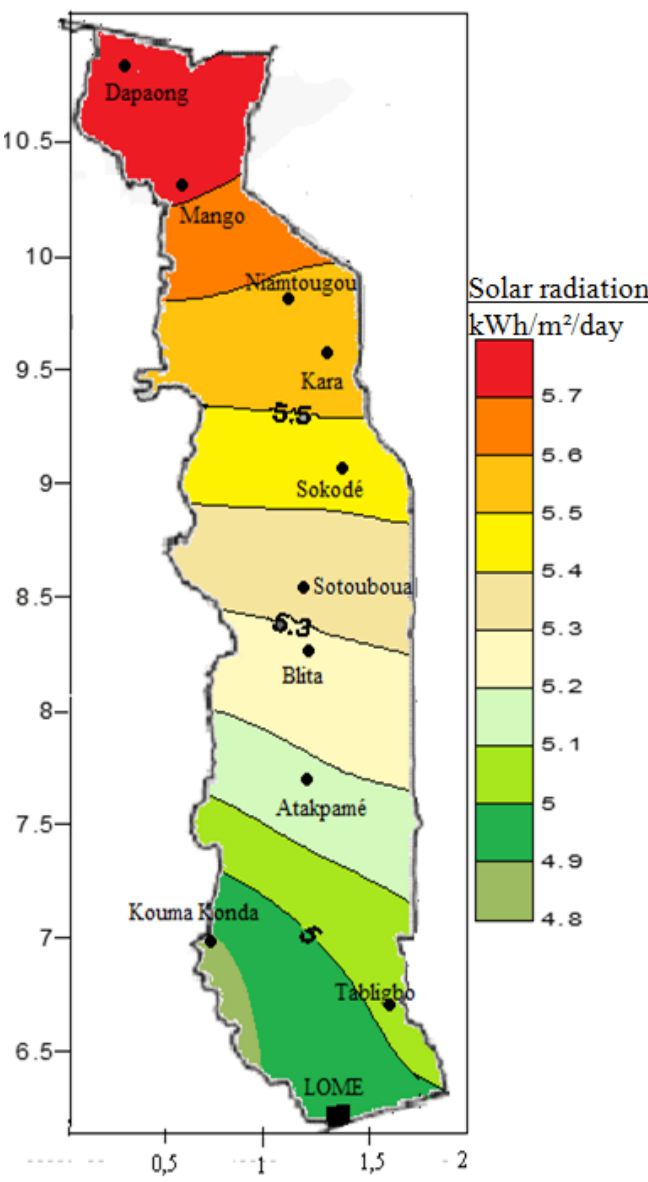

Figure 16. Solar radiation map of Togo in October 


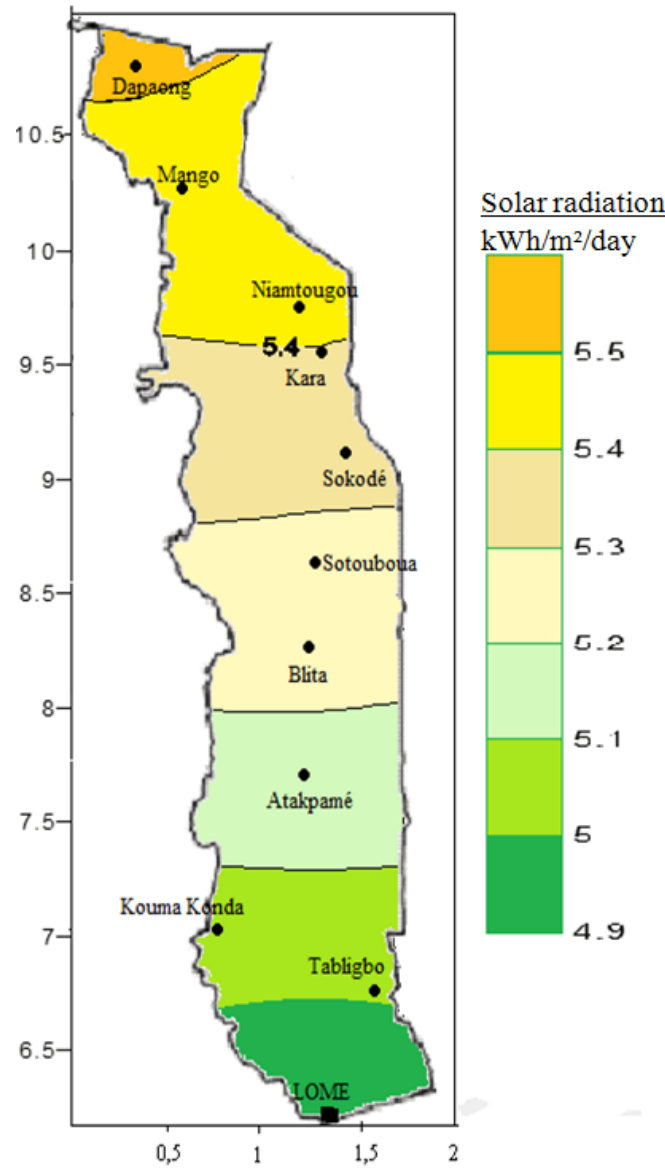

Figure 17. Solar radiation map of Togo in November

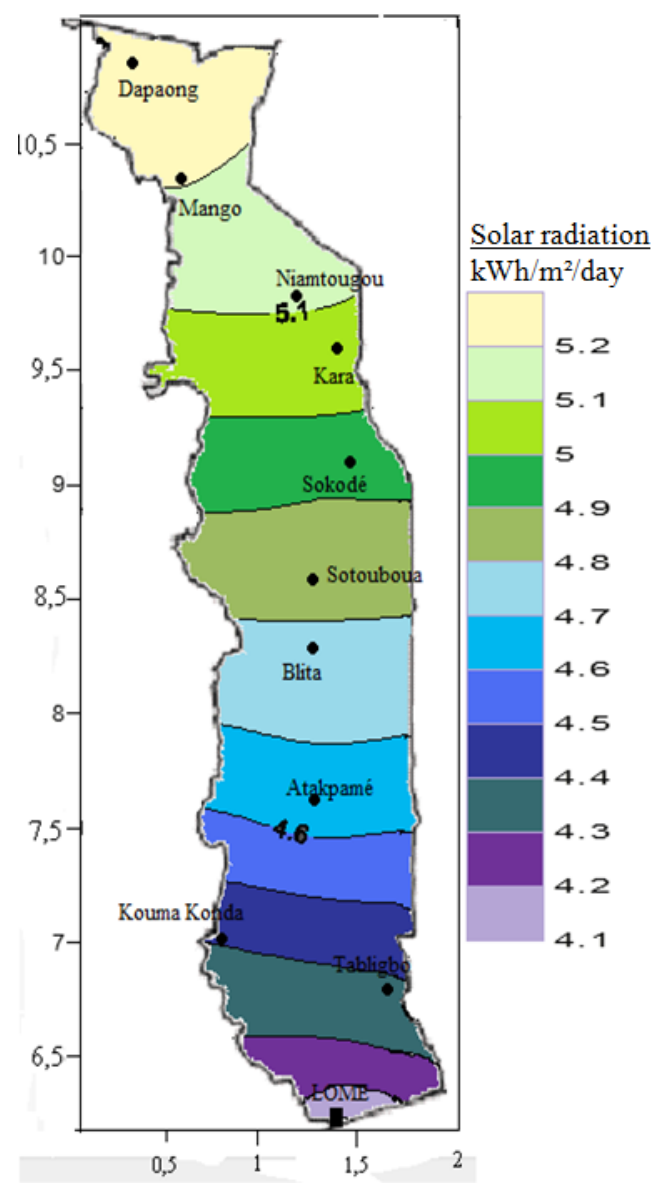

Figure 18. Solar radiation map of Togo in December
These results show that the solar radiation increases as the latitude of the place increases. The months of June July and August are very rainy in the central regio of Togo and it is a mountainous zone. Also the relative humidity is high during the same period compared to its value in the south and north of the country. This results show that solar radiation decreases in the central part of the country during this period compared to southern cities like Lomé, Tabligbo and the cities of Niamtougou, Mango and Dapaong.

\section{Conclusion}

The measured data were used to model the solar radiation for the various cities in Togo. Although the first models applied to Togo used only calculate solar radiation values at any time in the cities of measurement, the last method allowed us to determine with good precision the value of the solar radiation in several cities covering the Togolese geographical space. These values were used to establish the country's solar radiation maps for all months of the year. These maps will allow the technicians and engineers to have a precise idea of the solar radiation of Togo for an optimization of its exploitation. Besides, the classical methods are unable to generate solar radiation series in places where no solar information is available. Nevertheless, the methodology proposed is able to do this, it is more versatile than the classical methods, and so is able to draw maps of the zone. This methodology is easily extendible to other places. The only requirement is the knowledge of the hourly solar radiation from only 3 sites of the country where the map is going to be drawn.

\section{References}

[1] Angström, A., 1956. On the computation of global solar radiation from records of sunshine. Arkiv Geophysik 3(23), 551-556.

[2] Rietveld, M.R., 1978. A new method for estimating the regression coefficients in the formula relating solar radiation to sunshine. Agriculture Meteorology 19, 243-252.

[3] Newland, F.J., 1989. A study of solar radiation models for the coastal region of south China. Solar Energy 43(4), 227-235.

[4] Gopinathan, K., 1988. Computing the monthly mean daily diffuse radiation from clearness index and percent possible sunshine. Solar Energy 41 (4), 379-385.

[5] Akinoglu, B., Ecevit, A., 1990. Construction of a quadratic model using modified Angström coefficients to estimate global solar radiation. Solar Energy 45 (2), 85-92.

[6] Dorvlo, A., Ampratwum, B., 1999. Modeling of weather data for Oman. Renewable Energy 17, 421-428.

[7] Philips, W.F., 1984. Harmonic analysis of climatic data. Solar Energy 32 (3), 319-328.

[8] Herrero, A.C., 1993. Harmonic analysis of monthly solar radiation data in Spain. Ambient Energy 14 (1), 35-40.

[9] Rumelhart, D.E., Hinton, G.E., Williams, J.R., 1986. Learning Internal Representation by Error Propagation Parallel Distributed Processing: Explorations in the Microstructure of Cognition, vol. 1. MIT Press, MA, Cambridge (Chapter 8).

[10] Hertz, J., Krogh, A., Palmer, R., 1995. Introduction to the Theory of Neural Computation. Addison-Wesley, Canada.

[11] Declan Conway, Emma Archer van Garderen, Delphine Deryng, Steve Dorling, Tobias Krueger, Willem Landman, Bruce Lankford, Karen Lebek, Tim Osborn, Claudia Ringler, James Thurlow, Tingju Zhu, Carole Dalin, 2015. "Climate and southern Africa's water-energy-food nexus", in Nature Climate Change of Nature Publishing Group, 5 (9), 837. 
[12] Al-Alawi, S.M., Al-Hinai, H.A., 1998. An ANN-based approach for predicting global solar radiation in locations with no measurements. Renewable Energy 14(1-4), 199-204.

[13] Togrul, I.T., Onat, E., 1999. A study for estimating the solar radiation in Elazig using geographical and meteorological data. Energy Conversion and Management 40, 1577-1584.

[14] Kalogirou, S., Michanelides, S., Tymbios, F., 2002. Prediction of maximum solar radiation using artificial neural networks. In: Proceedings of the WREC VII, Germany.

[15] Sözen, A., Arcaklıo lu, E., O“ Zalp, M., 2004. Estimation of solar potential in Turkey by artificial neural networks usinage meteorological and geographical data. Energy Conversion and Management 45, 3033-3052.

[16] Yang, K., Koike, T., 2002. Estimating surface solar-radiation from upperair humidity. Solar Energy 72 (2), 177-186.

[17] Elizondo, D., Hoogenboom, G., McClendon, R., 1996. Development of a neural network to predict daily solar radiation. Agricultural and Forest Meteorology 71, 115-132.

[18] Mohandes, M., Rehman, S., Halawani, T.O., 1998. Estimation of global solar radiation using artificial neural networks. Renewable Energy 14 (1-4), 179-184.

[19] Mohandes, M., Balghonaim, A., Kassas, M., Rehman, S., Halawani, T.O., 2000. Use of radial basis functions for estimating monthly mean daily solar radiation. Solar Energy 68 (2), 161-168.

[20] Hontoria, L., Aguilera, J., Riesco, J., Zufiria, P., 2001. Recurrent neural supervised models for generating solar radiation synthetic series. Journal of Intelligent and Robotic Systems 31, 201-221.

[21] Hontoria, L., Aguilera, J., Zufi 'ria, P., 2002. Generation of hourly irradiation synthetic series using the neural network multilayer perceptron. Solar Energy 72, 441-446.

[22] Tasadduq, I., Rehman, S., Bubshait, K., 2002. Application of neural networks for the prediction of hourly mean surface temperature in Saudi Arabia. Renewable Energy 25, 545-554.

[23] Tymvios, F.S., Jacovides, C.P., Michaelides, S.C., Scouteli, C., 2005. Comparative study of Angström's and artificial neural networks' methodologies in estimating global solar radiation. Solar Energy 78, 752-762.
[24] Wasserman, P., 1993. Advanced Methods in Neural Computing. Van Nostrand Reinhold, New York.

[25] Lippmann, R.P., 1987. An Introduction to Computing with Neural Nets. IEEE ASSP Magazine, pp. 4-22.

[26] Bishop, C.M., 1996. Neural Networks for Pattern Recognition Oxford University Press, Oxford.

[27] Pham, D.T., Liu, X., 1995. Neural Networks for Identification, Predication and Control. Springer, London.

[28] Haykin, S., 1994. Neural Networks. A Comprehensive Foundation. Macmillan Publishing Company.

[29] Hornik, K., Stinchcombe, M., White, H., 1989. Multilayer feedforward networks are universal approximators. Neural Networks 2 (5), 359-366.

[30] Hontoria, L., Riesco, J., Zufiria, P., Aguilera, J., 1999. Improved generation of hourly solar radiation artificial series using neural networks. EANN99.

[31] Hontoria, L., Riesco, J., Zufiria, P., Aguilera, J., 2000. Application of neural networks in the solar radiation field. Obtainment of solar radiation maps. 16th European Photovoltaic Solar Energy Conference and Exhibition. Glasgow, 1-5 May.

[32] Zufiria, P., Vazquez, A., Riesco, J., Aguilera, J., Hontoria, L., 1999. A neural network approach for generating solar radiation artificial series. In: Proceedings of the (IWANN099). 4-5 June. Alicante, Spain.

[33] Chatelin, C., Les Multi Layer Perceptron (MLP) Nov 2003.

[34] Rude, J., Développement d'un modèle statistique neuronal pour la description fine de la pollution par le dioxyde d'azote : application à la région parisienne, Université Paris XII - Val de Marne, Thèse de doctorat, 2008.

[35] Ammar, Y. M., mise en œuvre de réseaux de neurones pour la modélisation de cinétiques réactionnelles en vue de la transposition batch/continu, Thèse de Doctorat de l'I.N.P. Toulouse -17 juillet 2007.

[36] Hontoria, L., Aguilera, J., Zufiria, P., 2005. An application of the multilayer perceptron: Solar radiation maps in Spain. Solar Energy 79, 523-530. 